المجلة العربية للعلوم

ونشـر الأبحـاث

المجلد (6)، العدد (4) : 30 ديسمبر 2020 م

ص: 135 - 148

\title{
Obstacles facing the application of the law of protection from abuse, from the point of view of workers in the Social Protection Department in Makkah Al-Mukarramah Region
}

\section{Fahad Ahmad Apopakr Almalki}

King Abdulaziz University $\|$ KSA

\begin{abstract}
The aim of the research is to uncover the obstacles facing the application of the law of protection from abuse, in the face of domestic violence, from the workers' point of view, using the case study approach. For collecting data, the study relied on the interview and simple observation tool. The research community consists of specialized workers in the three cities during the study period, as their number reached (41) employees. The most important results were an increase in the volume of reports of domestic violence and a steady increase, with the total number during the three years $(2107,2018$, and 2019), respectively $(4748,25375$, and 33085). The results showed that the Social Protection Unit in the three cities plays a good role in handling reports of domestic violence and dealing with them. It also showed the weakness of the work environment in all its details, in terms of offices, devices, electronic system and means of communication, the lack of transportation, the absence of a shelter in Makkah Al-Mukarramah and the need for many cases to enter the home and the difficulty of accepting cases in other regions. The lack of a cadre of social workers, psychologists and administrators, the lack of financial incentives, the lack of a cadre of social workers on par with the psychologists, the poor knowledge of some employees about the role of social protection, the absence of a task guide for the employees, the lack of specialized training courses, as well as the new psychological measures, the female employees assigned to the role observers inside the home are not qualified to deal with cases of protection and social work, the weak role of the authorities in cooperation with social protection, and the lack of awareness of the importance of their work, and the weak response of the police. In light of these results, a number of recommendations were developed to reduce these obstacles.
\end{abstract}

Keywords: Law of protection from abuse - Domestic Violence - Social Protection Department.

\section{المعوقات التي تواجه تطبيق نظام الحماية من الإيذاء \\ من وجهة نظر العاملين في إدارة الحماية الاجتماعية بمنطقة مكة المكرمة لماته}

\author{
فهد بن احمد أبو بكر المالكي \\ جامعة الملك عبد العزيز || المملكة العربية السعودية إيكاية
}

الملخص: هدف البحث إلى الكشف عن المعوقات التي تواجه تطبيق نظام الحماية من الإيذاء في مواجهة العنف الأسري من وجهة نظر

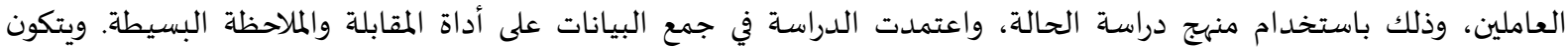

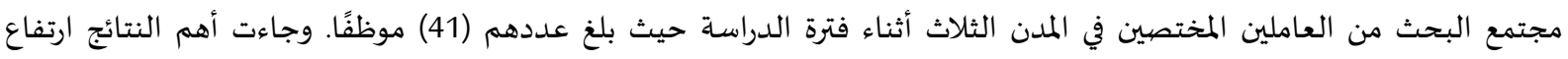

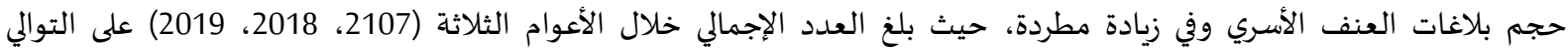

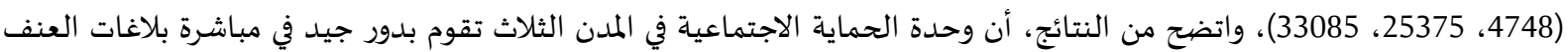


الأسري والتعامل معها، كما تبين ضعف بيئة العمل بجميع تفاصيلها من حيث المكاتب والأجهزة والنظام الإلكتروني ووسائل الاتصال،

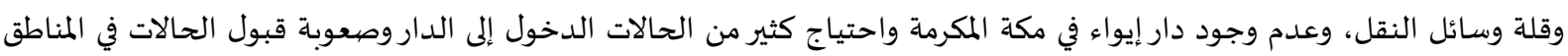

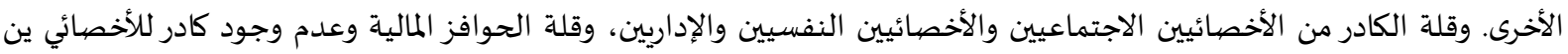

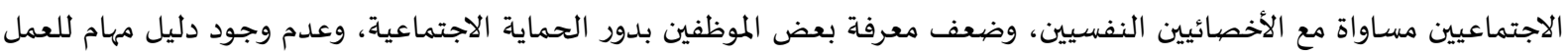

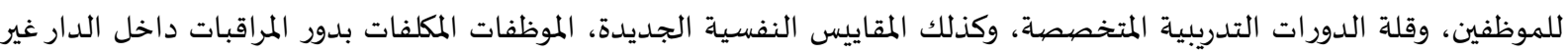
مؤهلات للتعامل مع حالات الحماية والعمل الاجتماعي، وضعف دور الجهات في التعاون مع الحماية الاجتماعية وعدم إدراك التهات أهمية

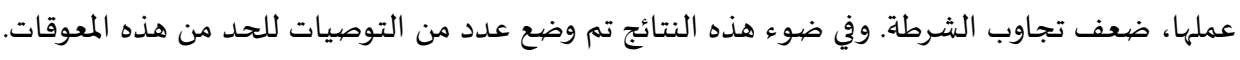
الكلمات المفتاحية: نظام الحماية من الإيذاء - العنف الأسري - إدارة الحماية الاجتماعية.

المقدمة:

لقد بدأ الاهتمام بالعنف الأسري عالميا من خلال وقوع العنف ضد المرأة على أنه انتهاك ضد حقوق

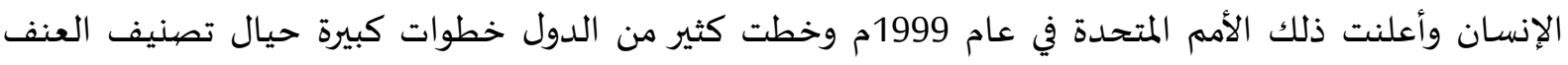

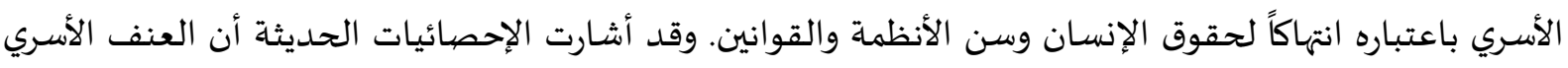

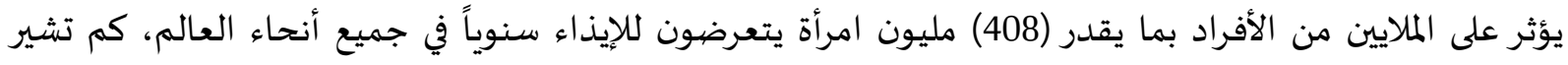

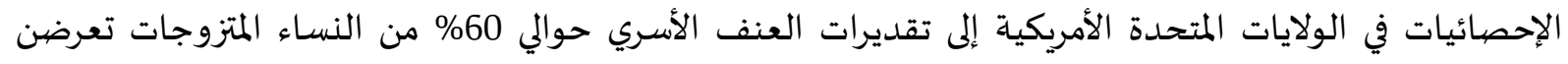

للاعتداء. (Payne, 2017).

ولا شك أن إن صددور نظام الحماية من الإيذاء في المملكة العربية السعودية خطوة إيجابية ومهمة لحماية

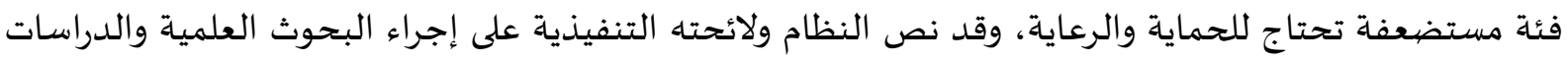
المتخصصة ذات العلاقة بالحماية من الإيذاء، وقد يكون هناك مشكلات تواجه تطبيق نظام الحماية من الإيذاء،

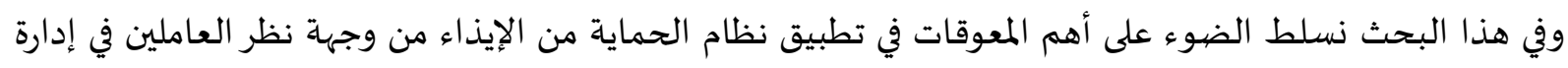
الحماية الاجتماعية بمنطقة مكة المكرمة.

مشكلة البحث:

شهد المجتمع السعودي في النصف الثاني من القرن العشرين كثير من التغيرات السريعة ابتداءً باكتشاف

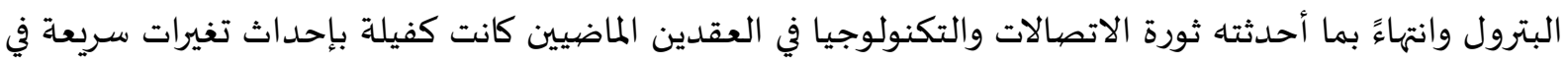

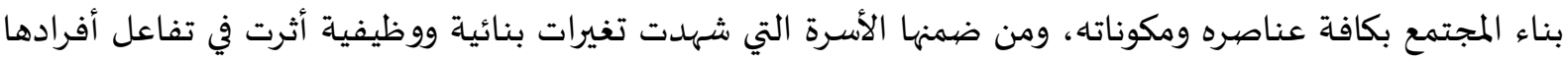

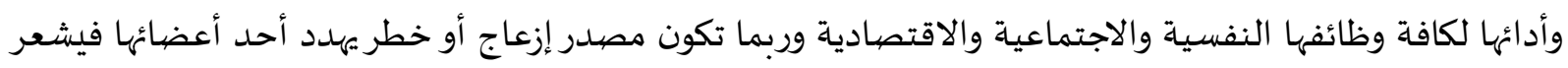
بعدم الأمان مثل ما نحن بصدده العنف الأسري، والذي يعتبر من أهم المشكلات التي لها أثر كبير في حياة الأفراد.

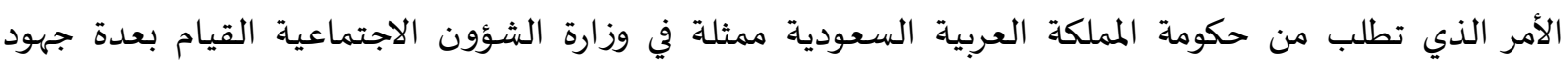

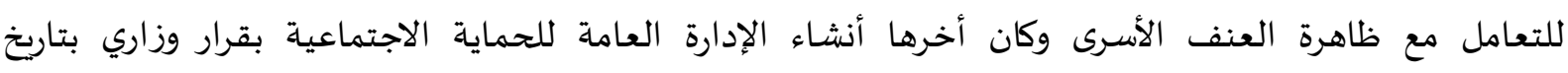

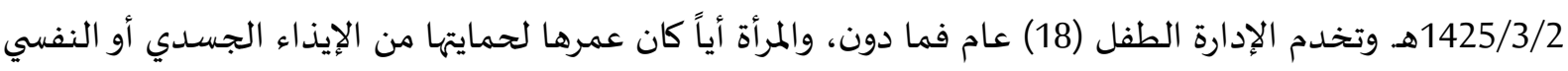

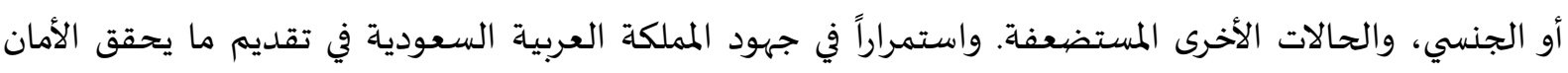

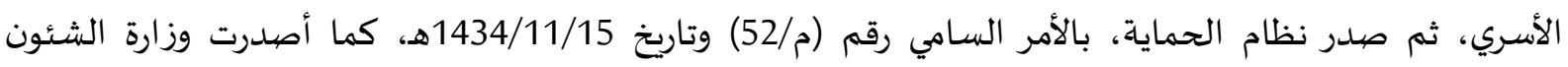

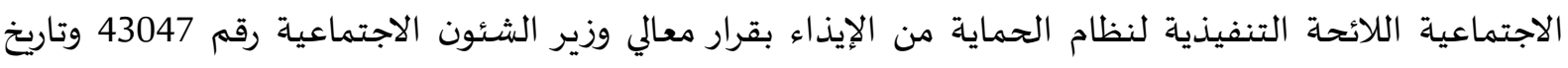

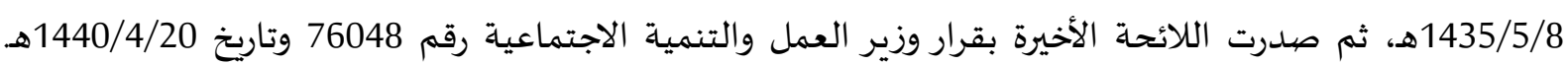


وقد ورد في إحصائيات وزارة العمل والشئون الاجتماعية للأعوام: (عام 2017 م، 2018، 2019) عدد بلاغات العنف الأسري في المملكة العربية السعودية.

$$
\text { جدول (1) إحصيائيات بلاغات العنف الأسري }
$$

\begin{tabular}{|c|c|}
\hline العام & 2017 \\
\hline 4748 & 2018 \\
\hline 25375 & 2019 \\
\hline
\end{tabular}

كما يشهد المجتمع السعودي كثير من التغيرات الاجتماعية والاقتصادية مما ينتج عنه كثير من التغيرات على دلى

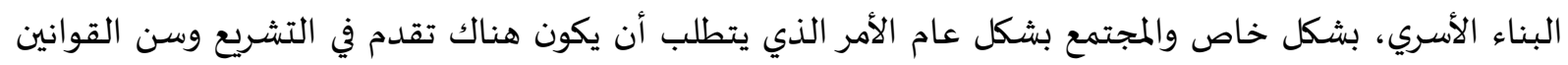

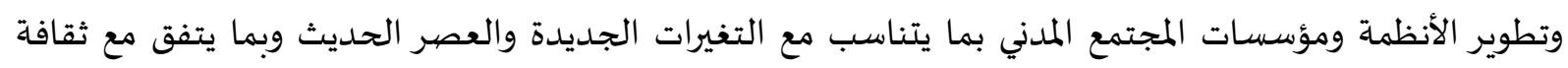

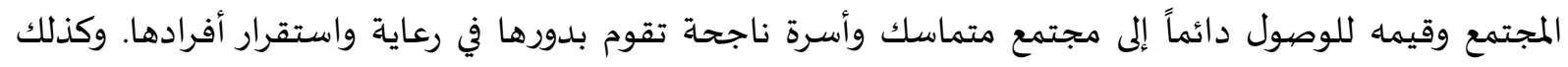

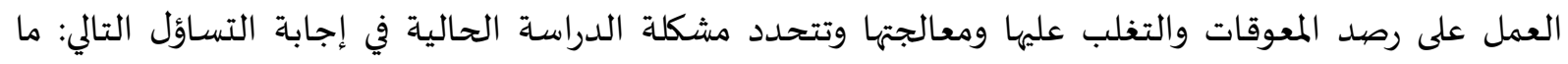

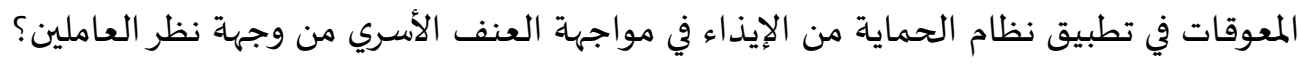

$$
\text { تساؤلات البحث: }
$$

يجيب البحث عن السؤال التالي: ما المعوقات في تطبيق نظام الحماية من الإيذاء في مواجهة العنف الأسري

$$
\text { من وجهة نظر العاملين؟ }
$$

$$
\text { هدف البحث: }
$$

يهدف البحث إلى الكشف عن المعوقات في تطبيق نظام الحماية من الإيذاء في مواجهة العنف الأسري من

وجهة نظر العاملين.

$$
\text { أهمية البحث: }
$$

الأهمية العلمية للبحث:

نظام الحماية من الإيذاء وهو نظام حديث صددر بتاريخ 8/ 5/ 1435هـ تم تطبيقه في المجتمع السعودي

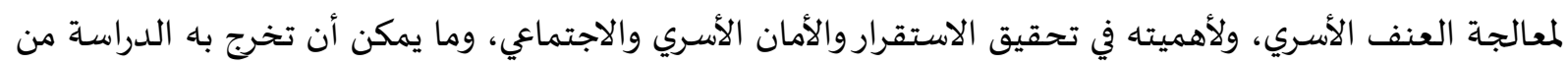

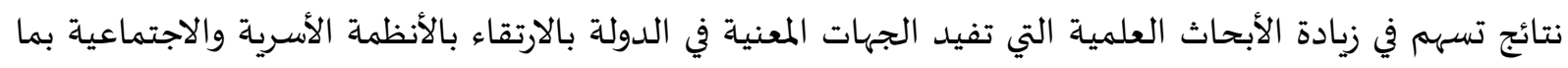
يتوافق مع خصوصية الأسرة السعودية ومواكبة التغيرات الجديدة.

الأهمية التطبيقية للبحث:

تتمثل الأهمية التطبيقية لهذا البحث في أهمية الوقوف على المعوقات في تطبيق نظام الحماية من الإيذاء

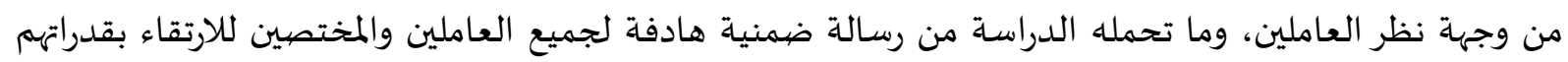
ومهاراتهم. 
الحدود الموضوعية: المعوقات التي تواجه تطبيق نظام الحماية من الإيذاء من وجهة نظر العاملين في إدارة الحماية الاجتماعية.

الحدود البشرية: الأخصائيين والأخصائيات الاجتماعيين والأخصائيين والأخصائيات النفسيين. الحدود المكانية: منطقة مكة المكرمة (وحدة الحماية الاجتماعية بمحافظة جدة، وحدة الحماية الاجتماعية بمحافظة الطائف، وحدة الحماية الاجتماعية بالعاصمة المقدسة).

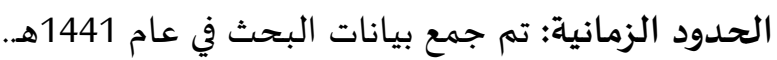

$$
\text { مفاهيم البحث: }
$$

- المعوقات: يعرفها الباحث بأنها كل المعوقات الإدارية، والتنظيمية، والإجرائية التي تؤثر على إداء العاملين في

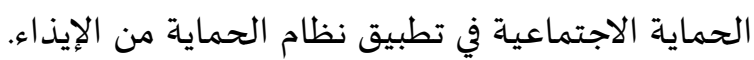

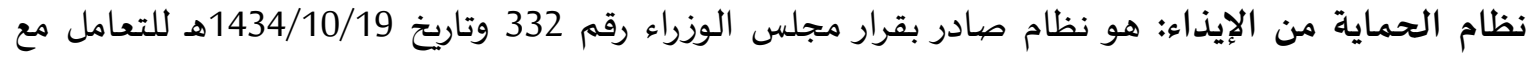
حالات العنف الأسري؛ المرأة المعنفة أيًا كان عمرها والطفل حتى سن الثامنة عشرة وذوي الحاجات الخاصة،

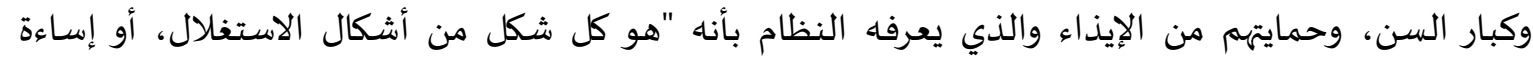

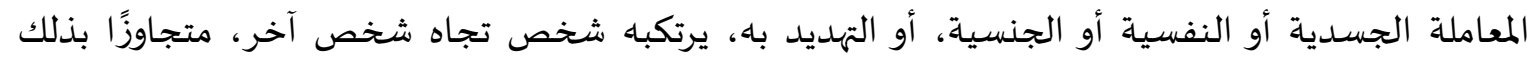

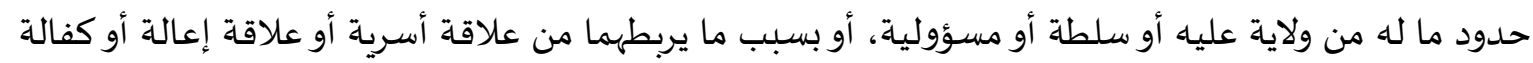

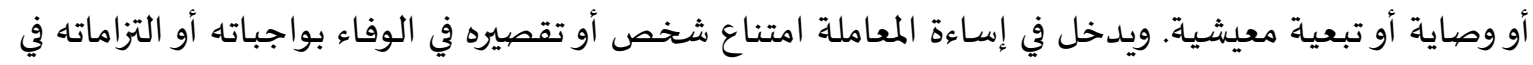

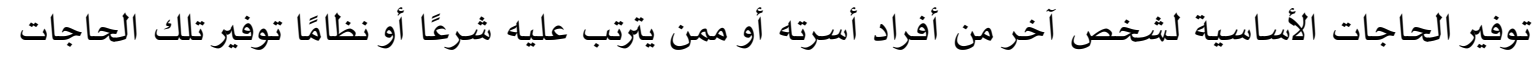

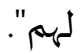
العنف الأسري: يعرفه الباحث بأنه كل فعل مقصود يقوم به أي فرد من أفراد الأسرة تجاه المرأة والأطفال من الأسرة ذاتها يلحق الأذى بهم ماديًا أو معنويًا. العنف ضيد المرأة: يعرف بأنه أي عمل أو تصرف عدائي، أو أو مؤذ أو مهيين، يرتكب بأية وسيلة، ويخلق لها معاناة

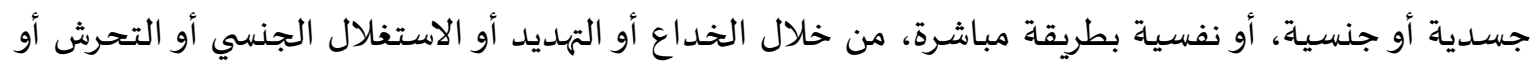

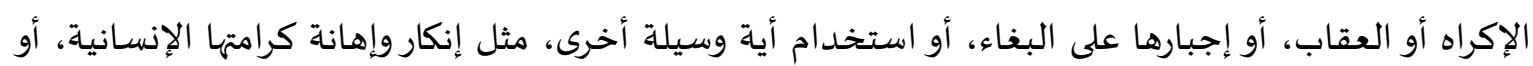

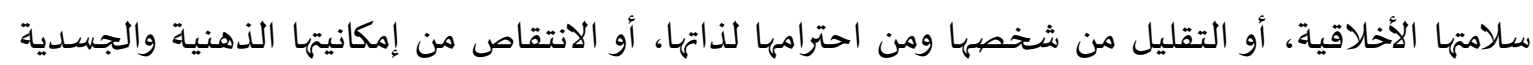
وصولاً للقتل. (كرادشة، 2009: 166).

2- 2 - الدراسـات السـابقة:

دراسة الدعجاني (2018) بعنوان: المعوقات التي تواجه الأخصائيين الاجتماعيين بلجان الحماية من العنف

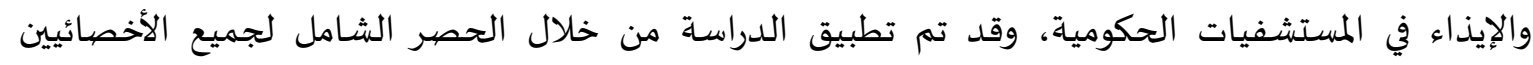

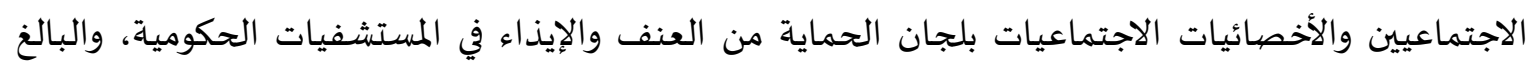

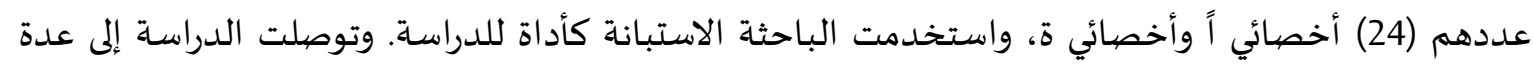

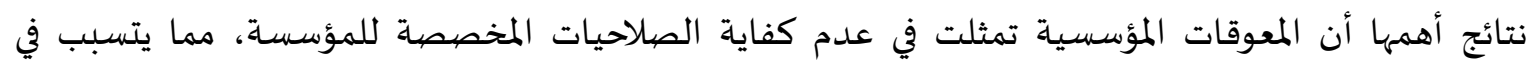
ضعف القدرة على مواجهة مشكلة العنف الأسري، وتلهيا قلة الموارد والإمكانات المخصصية المواجهة مشكلة الماتهات 
العنف الأسري من خلال لجان الحماية من العنف والإيذاء - قلة عدد الأخصائيين الاجتماعيين الذين يعملون في لجان الحماية من العنف والإيذاء.

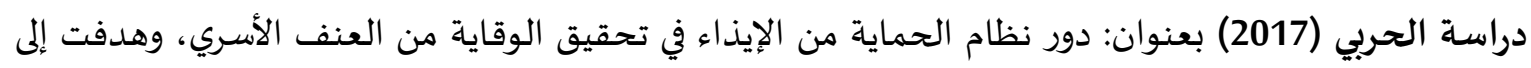

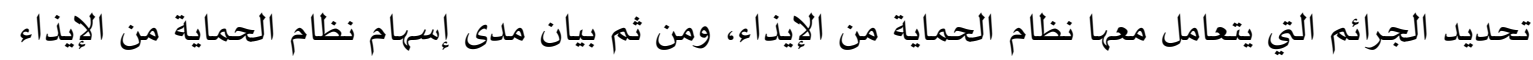

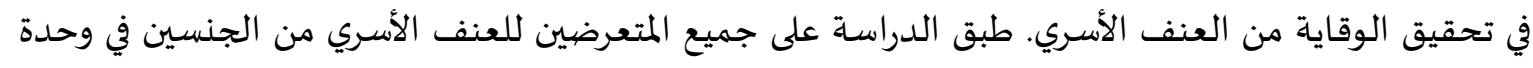

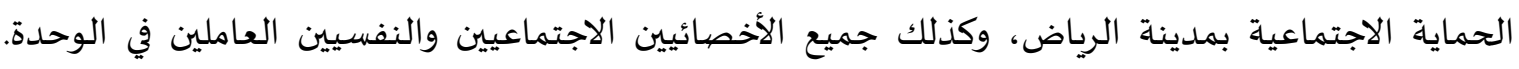

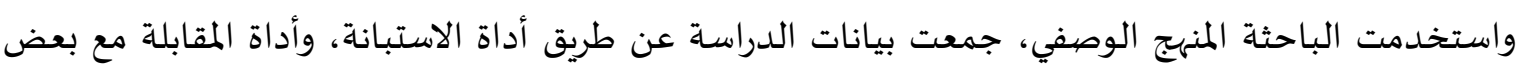

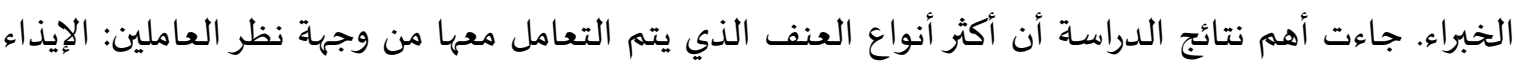

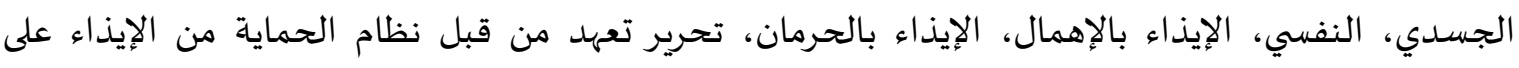

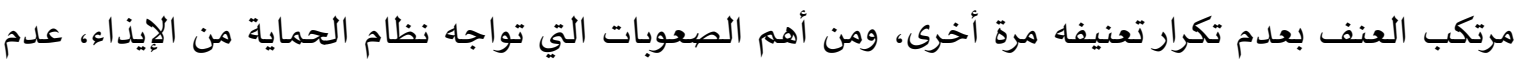

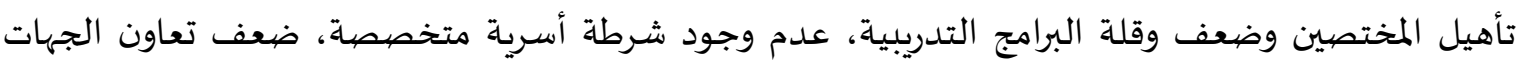

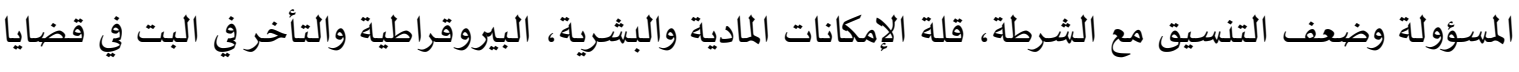
الحالات في المحاكم، وبعض الجهات المعنية، صعوبة التنسيق بين مختلف المؤسسات المدنية والجهات الأمنية، ضعف مستوى ومهارات العاملين في الحماية.

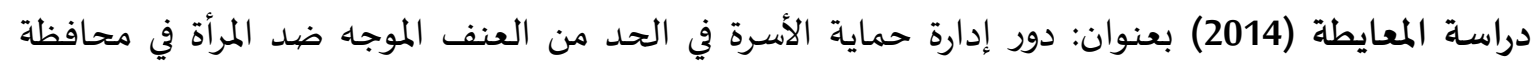

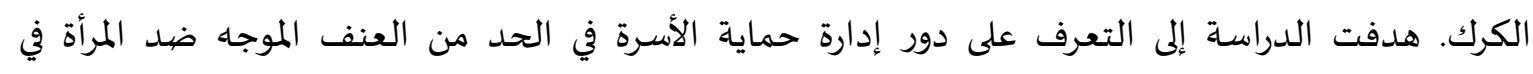

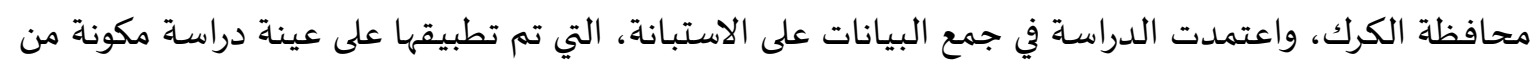

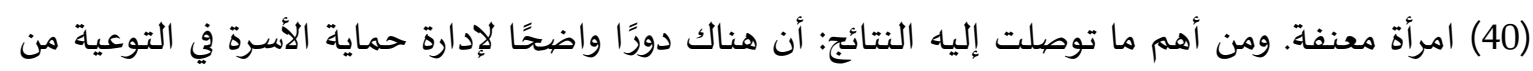

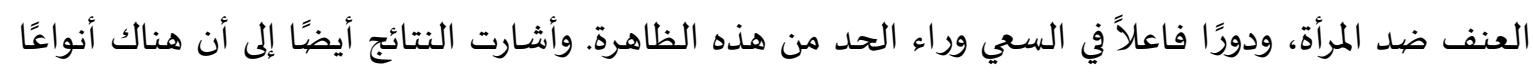
متعددة للعنف ضيد المرأة، منها العنف الجسدي والعنف الجنسي والعنف العنف النفسي والإهمال.

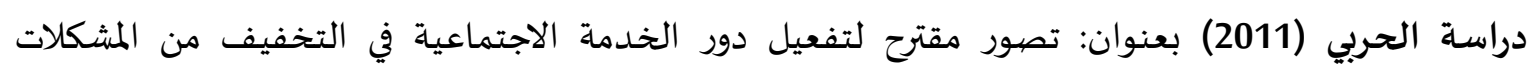

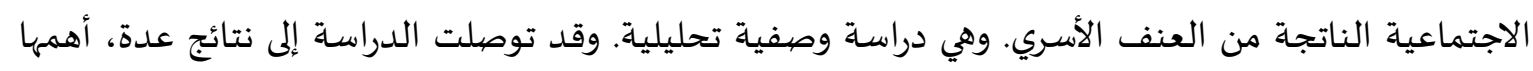

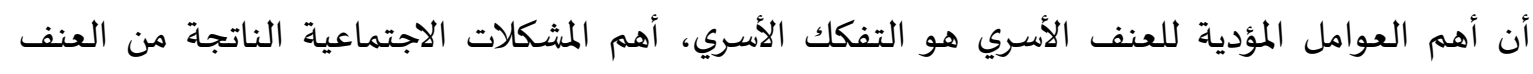

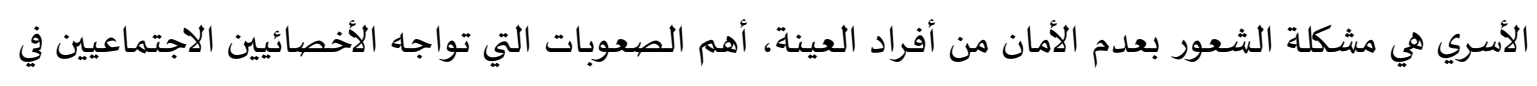

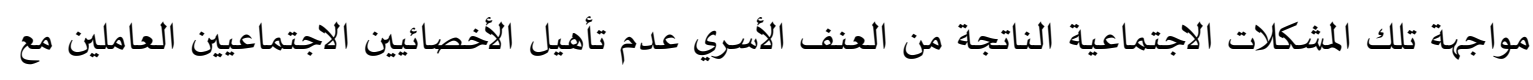
حالات العنف الأسري.

دراسـة : (Belshaku, 2016) هدفت إلى تحديد دور الأخصائيين الاجتماعيين في المراكز الوطنية لضحايا العنف

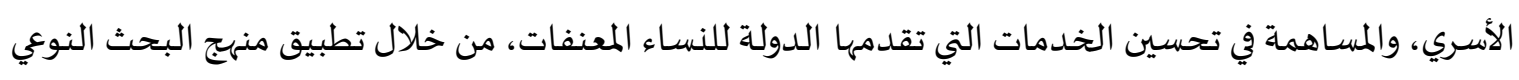

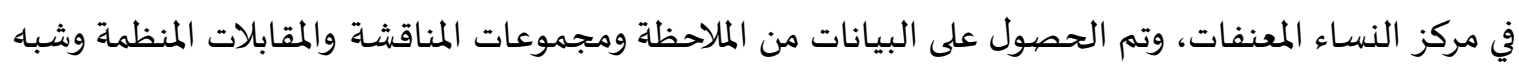

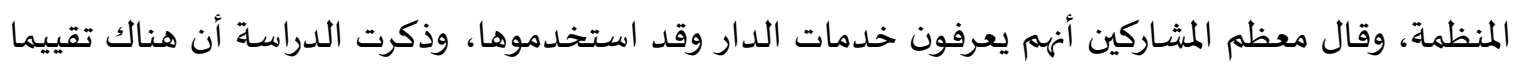

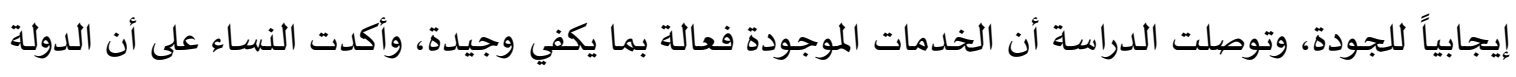
ينبغي أن تتدخل بشكل أكبر لتلبية احتياجاتهن، ويجب توسيع وتقوية دور الأخصائيين الاجتماعيين في المراكز الوطنية لضحايا العنف الأسري.

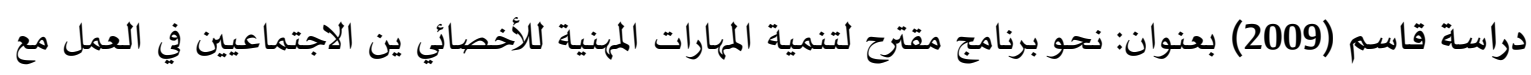

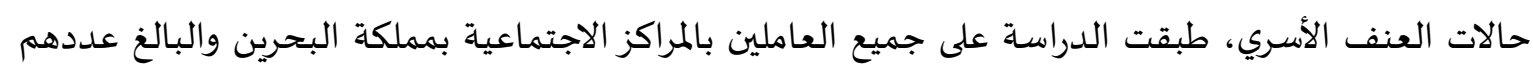




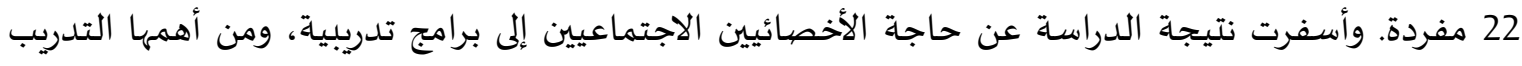

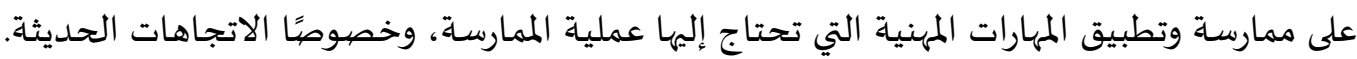

$$
\text { 3- منهجية البحث وإجراءاته. }
$$

هذا البحث وصفي تحليلي لوصف وتحليل معوقات نظام الحماية الاجتماعية في مواجهة العنف الأسري،

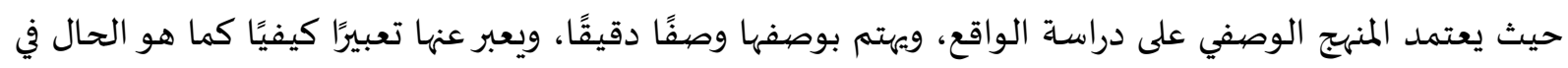

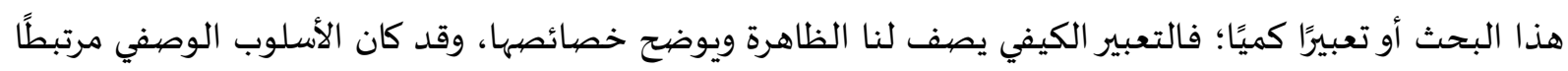

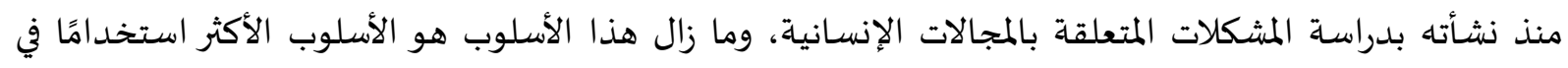

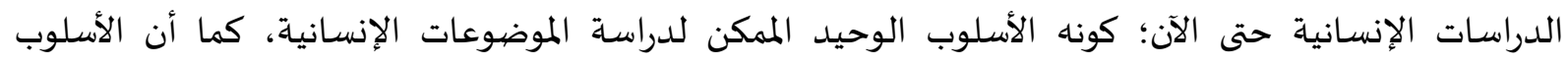

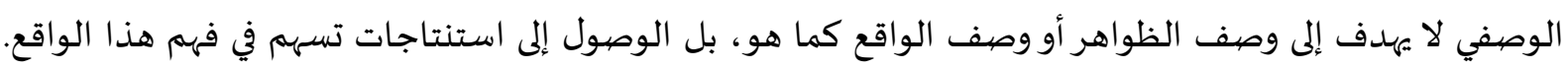

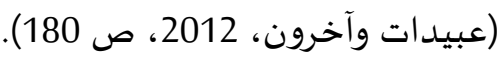

اعتمد البحث على منهج دراسة الحالة، وهي أحد أقسام المنهج أو البحث الوصفي، وتعني التعمق في بحث

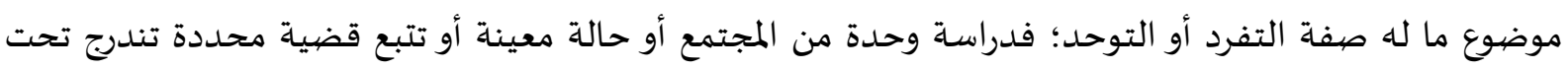

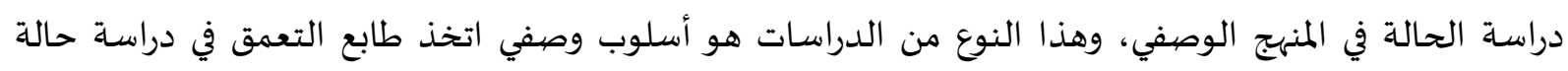

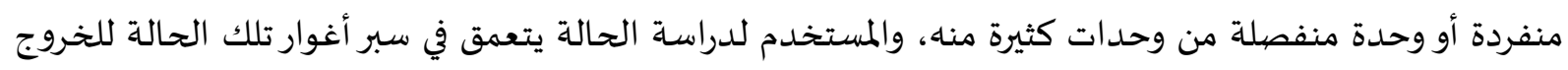

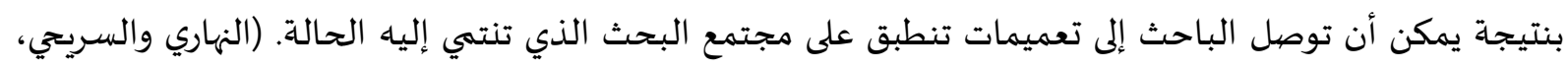

فقد التزم الباحث بمنهجية دراسـة الحالة في إجراء المقابلات بدأ باختيار الوقت المناسب لإجراء المقابلات

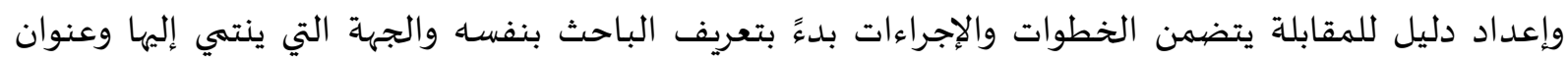

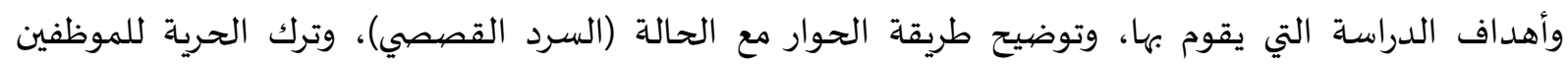

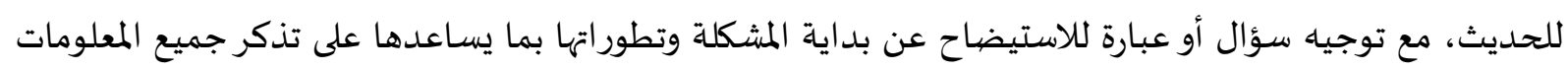

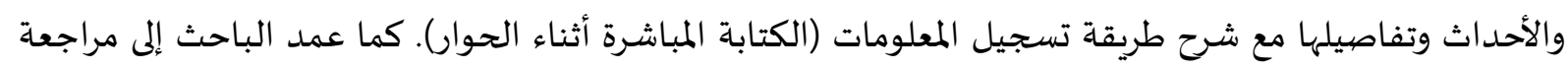

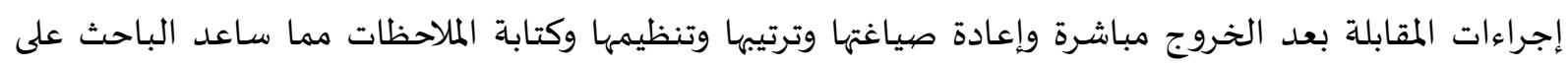

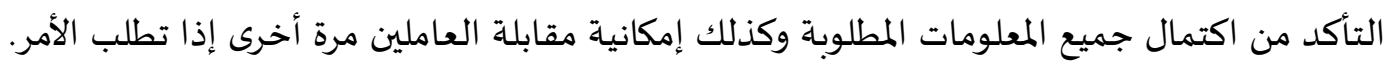

يتمثل مجتمع البحث من جميع العاملين من الأخصائيين والأخصائيات الاجتماعيين والأخصائيين والأخصائيات النفسيين. (محافظة جدة، مكة المكرمة، محافظة الطائف). والبالغ عددهم (41) مفردة، ونظراً لصغر

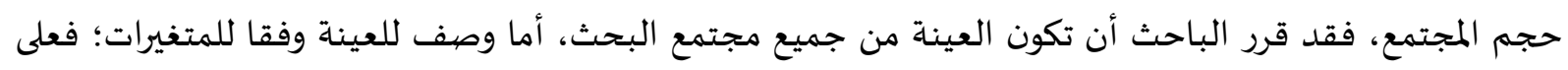
النحو الآتي: 
وصف عينة البحث:

النوع:

جدول رقم (1) توصيف عينة البحث تبعًا للنوع

\begin{tabular}{|c|c|c|c|c|c|c|c|c|}
\hline \multicolumn{2}{|c|}{ المجموع } & \multicolumn{2}{|c|}{ مكة المكرمة } & \multicolumn{2}{|c|}{ محافظة جدة } & \multicolumn{2}{|c|}{ محافظة الطائف } & \multirow{2}{*}{ النوع } \\
\hline النسبة & العدد & النسبة & العدد & النسبة & العدد & النسبة & العدد & \\
\hline 53.7 & 22 & 55.6 & 5 & 57.7 & 15 & 33.3 & 2 & ذكر \\
\hline 46.3 & 19 & 44.4 & 4 & 42.3 & 11 & 66.7 & 4 & أنثى \\
\hline$\% 100$ & 41 & $\% 100.0$ & 9 & $\% 100.0$ & 26 & $\% 100.0$ & 6 & الإجمالي \\
\hline
\end{tabular}

يتبين من الجدول (1) أن مجتمع البحث موزع بين الذكور والإناث، حيث اتضح أن (53.7\%) منهم من

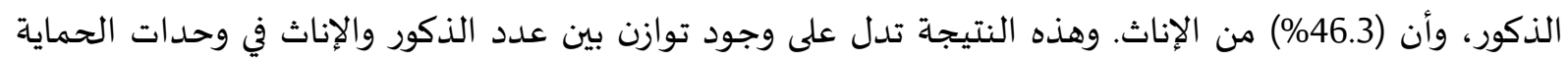
الاجتماعية في المدن الثلاث (جدة، ومكة المكرمة، والطائف)، وهو ما يعبر عن ميزة إيجابية في هذا المجال وهد المال الاجتماعي

جدول رقم (2) توصيف عينة البحث تبعًا للفئة العمرية

\begin{tabular}{|c|c|c|c|c|c|c|c|c|}
\hline \multicolumn{2}{|c|}{ المجموع } & \multicolumn{2}{|c|}{ مكة المكرمة } & \multicolumn{2}{|c|}{ محافظة جدة } & \multicolumn{2}{|c|}{ محافظة الطائف } & \multirow{2}{*}{ فئات العمر } \\
\hline النسبة & العدد & النسبة & العدد & النسبة & العدد & النسبة & العدد & \\
\hline 34.1 & 14 & 33.3 & 3 & 42.3 & 11 & - & - & أقل من 40 سنة \\
\hline 41.5 & 17 & 33.3 & 3 & 34.6 & 9 & 83.3 & 5 & من 40- 45 سنة \\
\hline 24.4 & 10 & 33.3 & 3 & 23.1 & 6 & 16.7 & 1 & أكثر من 45 سنة \\
\hline \%100 & 41 & \%100.0 & 9 & $\% 100.0$ & 26 & \%100.0 & 6 & الإجمالي \\
\hline
\end{tabular}

يتضح من الجدول (2) أن غالبية موظفي وموظفات وحدات الحماية الاجتماعية في المدن الثلاث (جدة،

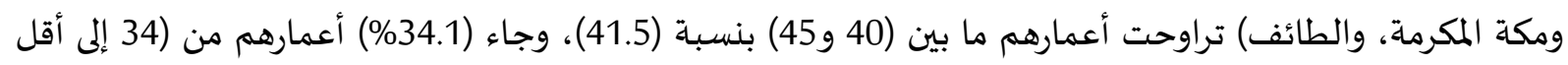

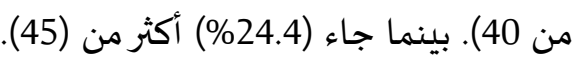

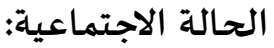

جدول رقم (3) توصيف عينة البحث تبعًا للحالة الاجتماعية

\begin{tabular}{|c|c|c|c|c|c|c|c|c|}
\hline \multicolumn{2}{|c|}{ المجموع } & \multicolumn{2}{|c|}{ مكة المكرمة } & \multicolumn{2}{|c|}{ محافظلة جدة } & \multicolumn{2}{|c|}{ محافظة الطائف } & \multirow{2}{*}{ الاجتماعية } \\
\hline النسبة & العدد & النسبة & العدد & النسبة & العدد & النسبة & العدد & \\
\hline 73.2 & 30 & 66.7 & 6 & 69.2 & 18 & 100.0 & 6 & متزوج \\
\hline 7.3 & 3 & 11.1 & 1 & 7.7 & 2 & - & - & غير متزوج \\
\hline 17.1 & 7 & 22.2 & 2 & 19.2 & 5 & - & - & مطلق \\
\hline 2.4 & 1 & - & - & 3.8 & 1 & - & - & أرمل ل \\
\hline$\% 100$ & 41 & $\% 100.0$ & 9 & $\% 100.0$ & 26 & $\% 100.0$ & 6 & الإجمالي \\
\hline
\end{tabular}

يتضح من الجدول السابق (3) أن أكبر نسبة من أفراد مجتمع البحث متزوجون، حيث بلغت نسبتهم

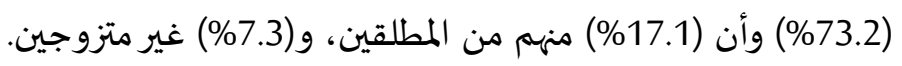


المؤهل العلمي:

جدول رقم (4) توصيف عينة البحث تبعاً للمؤهل العلمي

\begin{tabular}{|c|c|c|c|c|c|c|c|c|}
\hline \multicolumn{2}{|c|}{ المجموع } & \multicolumn{2}{|c|}{ مكة المكرمة } & \multicolumn{2}{|c|}{ محافظة جدة } & \multicolumn{2}{|c|}{ محافظة الطائف } & \multirow{2}{*}{ المؤهل العلمي } \\
\hline النسبة & العدد & النسبة & العدد العد & النسبة & العدد & النسبة & العدد & \\
\hline 85.4 & 35 & 77.8 & 7 & 84.6 & 22 & 100.0 & 6 & بكالوريوس \\
\hline 14.6 & 6 & 22.2 & 2 & 15.4 & 4 & - & - & ماجستير \\
\hline$\% 100$ & 41 & \%100.0 & 9 & \%100.0 & 26 & \%100.0 & 6 & الإجمالي \\
\hline
\end{tabular}

يتضح من الجدول السـابق (4) أن غالبية أفراد مجتمع البحث من الحاصلين على البكالوريوس، وذلك بنسبة قدرها (85.4\%)، كما تبين أن (14.6\%) منهم من الحاصلين على درجة الماجستير، وذلك بنسبة قدرها (14.6\%). وهذه النتيجة تدل على أن المؤهل العلهي للعاملين في وحدات الحماية الاجتماعية في المدن المدروسة الماتية مناسبة إلى حد كبير.

جدول رقم (5) توصيف عينة البحث تبعًا للتخصص

\begin{tabular}{|c|c|c|c|c|c|c|c|c|}
\hline \multicolumn{2}{|c|}{ المجموع } & \multicolumn{2}{|c|}{ مكة المكرمة } & \multicolumn{2}{|c|}{ محافظة جدة } & \multicolumn{2}{|c|}{ محافظة الطائف } & \multirow{2}{*}{ التخصص } \\
\hline النسبة & العدد & النسبة & العدد & العدد العد & العدد & النسبة & العدد العد & \\
\hline 31.7 & 13 & 88.9 & 7 & 7.7 & 2 & 66.7 & 4 & خدمة اجتماعية \\
\hline 43.9 & 18 & 11.1 & 2 & 57.7 & 15 & 16.7 & 1 & علم اجتماع \\
\hline 24.4 & 10 & - & - & 34.6 & 9 & 16.7 & 1 & علم نفس \\
\hline$\% 100$ & 41 & \%100.0 & 9 & $\% 100.0$ & 26 & $\% 100.0$ & 6 & الإجمالي \\
\hline
\end{tabular}

يوضح الجدول رقم (5) توصيف مجتمع البحث وفقاً للتخصص، وتشير النتائج في الجدول إلى أن (43.9\%) من مجتمع البحث تخصصهم علم الاجتماع، وأن (31.7\%) منهم تخصصيهم خدمة اجتماعية، كما تبين أن (24.4\%) منهم تخصصهم علم النفس. وهذه النتيجة تشير إلى أن تخصصيات العاملين في وحدات الحماية الاجتماعية في المدند المدروساة مناسبة إلى حد كبير، حيث إن طبيعة العمل في هذه الوحدات يتطلب هذه التخصصيات الثلاث والتي تكمل تحل

بعضها البعض.

جدول رقم (6) توصيف عينة البحث تبعًا للعمل

\begin{tabular}{|c|c|c|c|c|c|c|c|c|}
\hline \multicolumn{2}{|c|}{ المجموع } & \multicolumn{2}{|c|}{ مكة المكرمة } & \multicolumn{2}{|c|}{ محافظة جدة } & \multicolumn{2}{|c|}{ محافظة الطائف } & \multirow{2}{*}{ العمل الفعلي } \\
\hline النسبة الن & العدد العد & النسبة الن & 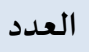 & النسبة & العدد العد & النسبة & العدد العد & \\
\hline 39 & 16 & 22.2 & 2 & 46.2 & 12 & 33.3 & 2 & أخصائي اجتماعي \\
\hline 17.1 & 7 & 44.4 & 4 & 3.8 & 1 & 33.3 & 2 & باحث اجتماعي \\
\hline 2.4 & 1 & 11.1 & 1 & - & - & - & - & باحث اجتماعي مسـاعد \\
\hline 24.4 & 10 & - & - & 34.6 & 9 & 16.7 & 1 & أخصائي نفسي \\
\hline 2.4 & 1 & 11.1 & 1 & - & - & - & - & مدير الوحدة \\
\hline 4.9 & 2 & - & - & 3.8 & 1 & 16.7 & 1 & مسـاعد مدير الوحدة \\
\hline 7.3 & 3 & & & 11.5 & 3 & - & - & مباشرة البلاغات \\
\hline 2.4 & 1 & 11.1 & 1 & - & - & - & - & مشرفة \\
\hline \%100 & 41 & $\% 100.0$ & 9 & \%100.0 & 26 & $\% 100.0$ & 6 & الإجمالي \\
\hline
\end{tabular}


بينت نتائج البحث، أن جميع العاملين المختصين في الحماية والذي تم إجراء المقابلات معهم هم أخصائي

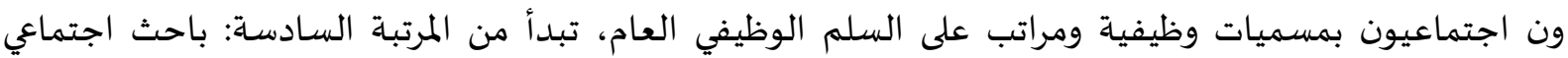

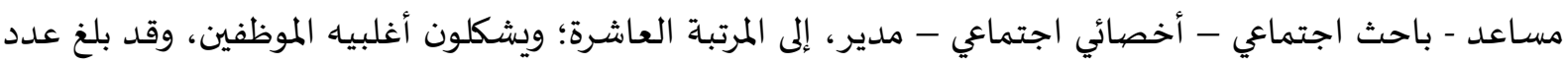

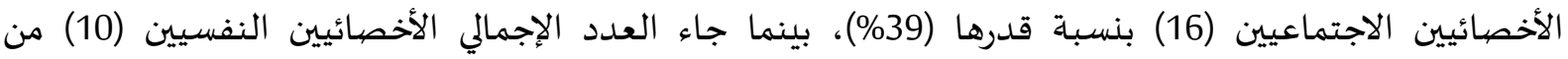

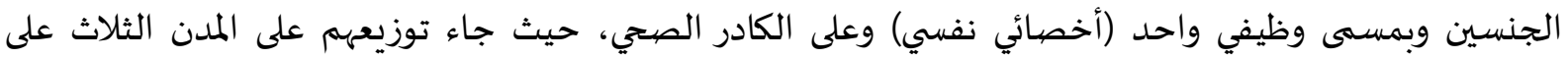
النحو التالي جدة (9)، وأخصائي ة واحدة في الطائف، أما مكاة فلا يوجد فيها أي أخصائي أو أخصائي ة نفسئي أخسية.

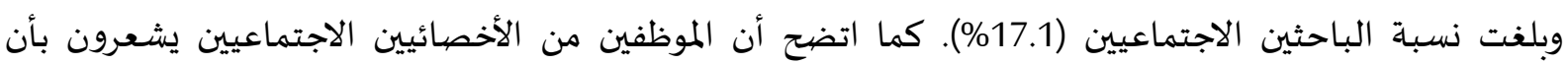
هناك تمييزًا وظيفيًا بينهم وبين الأخصائيين النفسيين لعدم تعيينهم على الكادر الصيني مقارنة بالأخصائيين النفسيين. جدول رقم (7) توصيف عينة البحث تبعاً لمدة الخدمة

\begin{tabular}{|c|c|c|c|c|c|c|c|c|}
\hline \multicolumn{2}{|c|}{ المجموع } & \multicolumn{2}{|c|}{ مكة المكرمة } & \multicolumn{2}{|c|}{ محافظة جدة } & \multicolumn{2}{|c|}{ محافظة الطائف } & \multirow{2}{*}{ 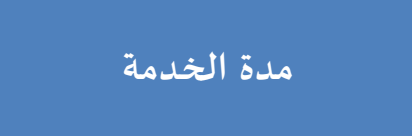 } \\
\hline 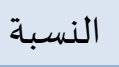 & 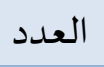 & النسبة ال & 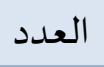 & النسبة الن & 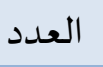 & النسبة & العدد العد & \\
\hline 58.5 & 24 & 44.4 & 4 & 57.7 & 15 & 83.3 & 5 & أقل من 5 سنوات \\
\hline 17.1 & 7 & - & - & 26.9 & 7 & - & - & من 5 إلى أقل من 10 سنوات \\
\hline 24.4 & 10 & 55.6 & 5 & 15.4 & 4 & 16.7 & 1 & 10 سنوات \\
\hline$\% 100$ & 41 & $\% 100.0$ & 9 & $\% 100.0$ & 26 & $\% 100.0$ & 6 & الإجمالي \\
\hline
\end{tabular}

تشير البيانات في الجدول السابق رقم (7) إلى أن أكبر نسبة من أفراد مجتمع البحث مدة خدمتهم أقل من

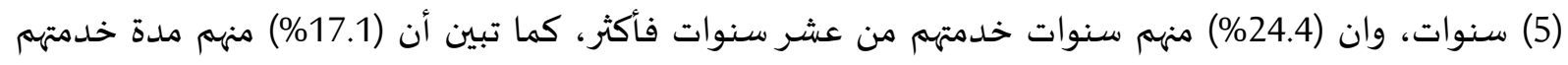

$$
\text { من (5) إلى (10) سنوات. }
$$

أولاً: المقابلة: قام الباحث بتصيميم دليل للمقابلة، لمجتمع البحث من الموظفين؛ ويتضمن مجموعة من الأسئلة المفتوحاة بما يتيح للمبحوثين من العاملين حرية التعبير عن آرائهم.

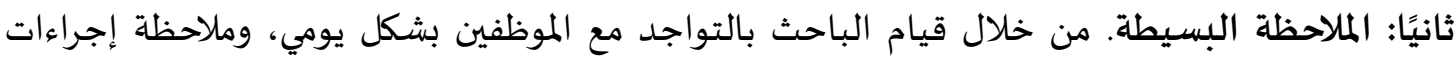

ورصد وتسجيل المعلومات والبيانات التي يلاحظها.

$$
\text { الأساليب الإحصائية لتحليل البيانات: }
$$

انتهت عملية جمع البيانات بكم كبير من المعلومات والملاحظات، وكان لاستخدام دليهات الماتل المقابلة أهمية كبيرة

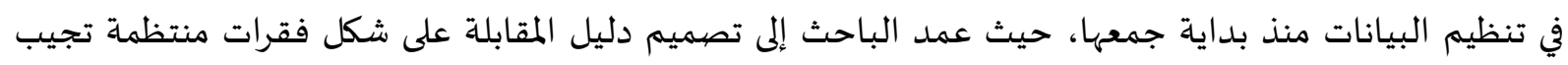

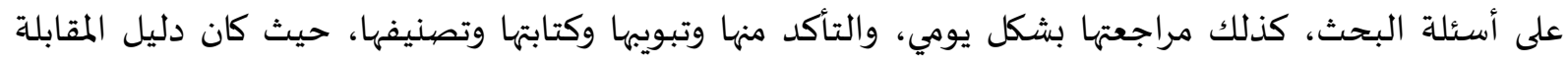

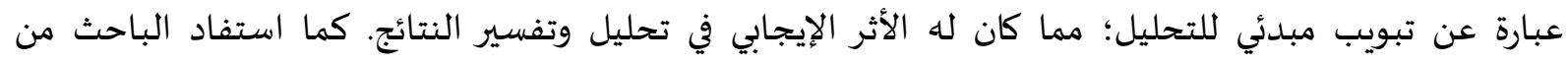

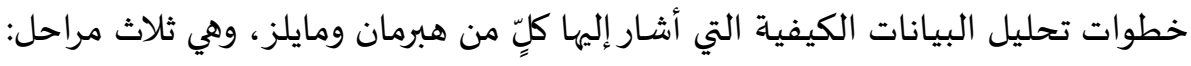
1- - مرحلة اختصار البيانات:

وفي هذه المرحلة قام الباحث بمراجعة البيانات وإعادة كتابتها وصياغتها وتصنيفها وترميزها، واستخدام

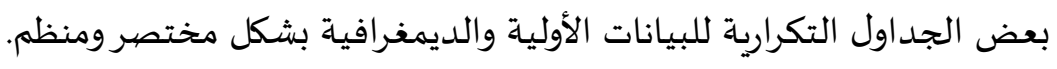




$$
\text { 2- 2 - مرحلة عرض البيانات: }
$$

وفي هذه المرحلة قام الباحث بتنظيم وترتيب عرض البيانات بصورة تسمح باستخلاص النتائج.

$$
\text { 3- مرحلة استخلاص النتائج: }
$$

في هذه المرحلة تم استخدام بعض الإجراءات الاستراتيجية، ومن أهمها: البحث عن البيانات المتشابهة

$$
\text { والمتغايرة، والقراءة المتكررة للبيانات، ومن ثم استخلاص النتائج ومراجعتها أكثر من مرة. }
$$

\section{4- 4رض نتائج البحث ومناقشتها.}

1- النتائج المتعلقة بحجم بلاغات العنف الأسري:

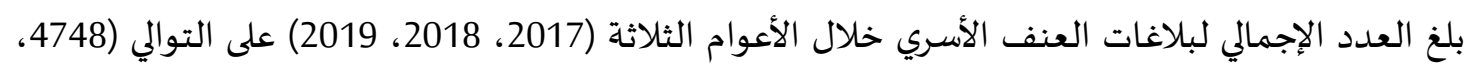

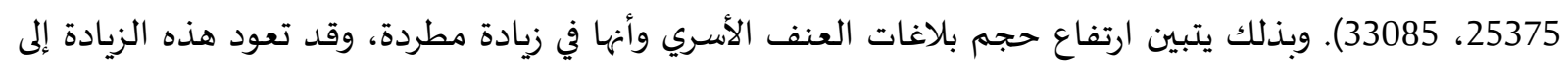

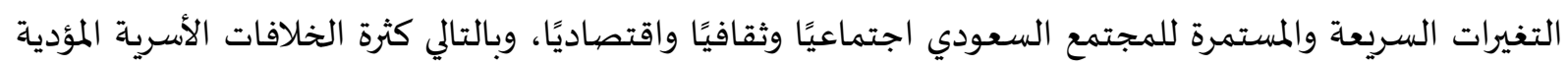
إلى العنف الأسري.

\begin{tabular}{|c|c|c|}
\hline النسبة & العدد العد & أنواع العنف \\
\hline 27 & 37 & العنف الجسـدي \\
\hline 25.1 & 35 & العنف النفسي \\
\hline 16.1 & 22 & الإهمال \\
\hline 15.3 & 21 & التحرش الجنسي \\
\hline 14.6 & 20 & التحرش اللفظي \\
\hline 1.5 & 2 & العنف الاقتصادي \\
\hline$\% 100$ & 137 & الإجمالي \\
\hline
\end{tabular}

2- - أنواع العنف تجاه الحالات المعنفة: جدول رقم (8) أنواع العنف تجاه الحالات المعنفة

اتضح من النتائج أن وحدة الحماية الاجتماعية في المدن الثلاث تقوم بدور جيد في مباشرة بلاغات العنف

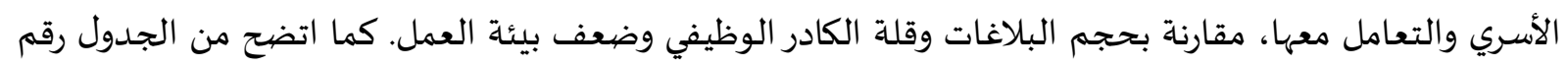

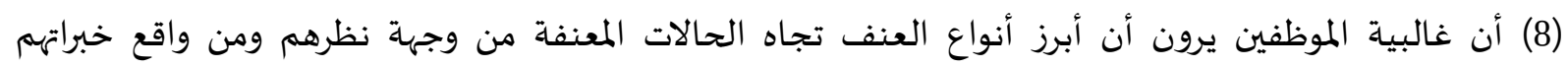

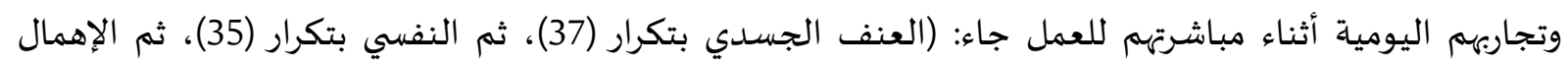

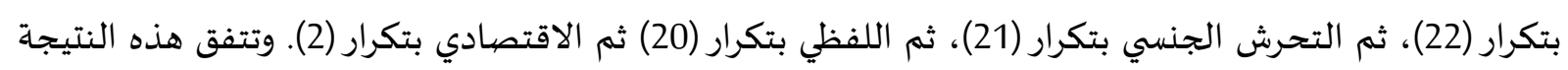

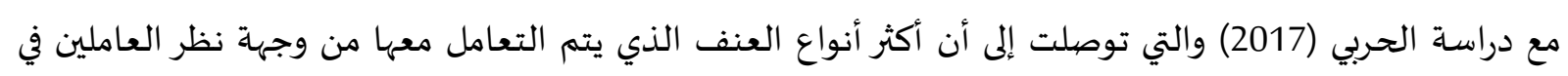

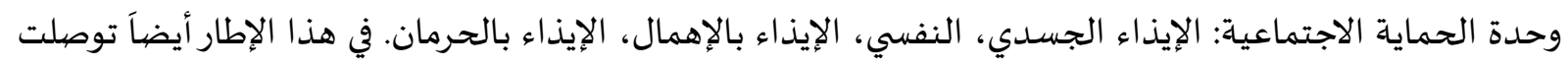

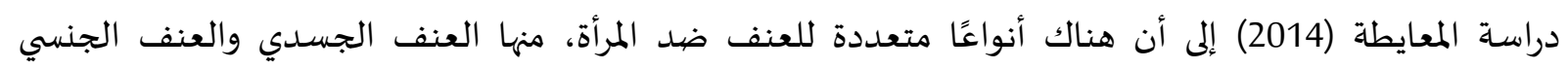
والعنف النفسي والإهمال.

3- أسباب العنف: كشفت البحث عن أن التفكك الأسري من أكثر الأسباب المؤدية إلى للعنف الأسري ثم تأتي بقية

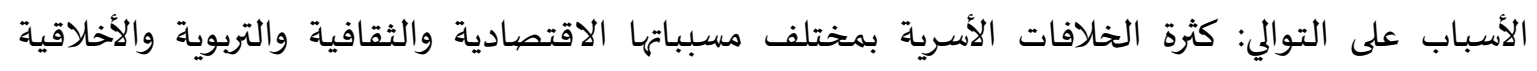

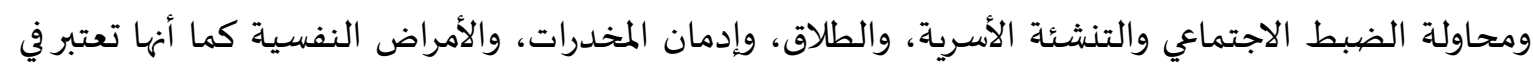


نهاية الأمر سبب مباشر في التفكك الأسري، ويتضح لنا التداخل بين أسباب العنف فقد يكون أحدها سببًا مباشراً والآخر نتيجة له أو العكس كالطلاق والتفكك الأسري على سبيل التفكيل المثال.

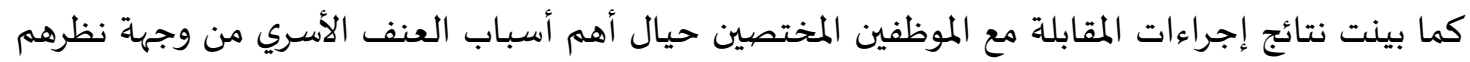

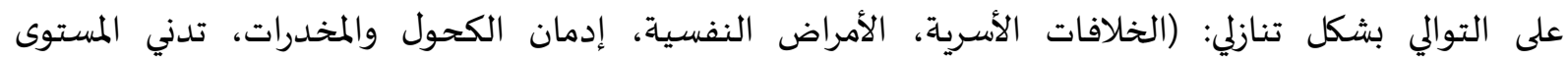

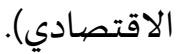

وفي هذا الإطار أشارت الحربي (2017) إلى أن التفكك الأسري يؤدي إلى انهيار الوحدة الأساسية، وانحلال

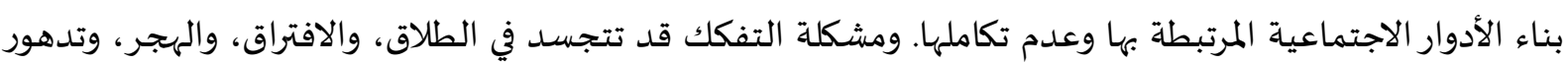

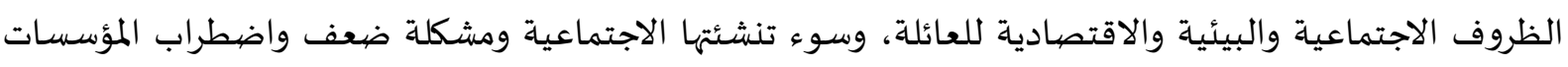

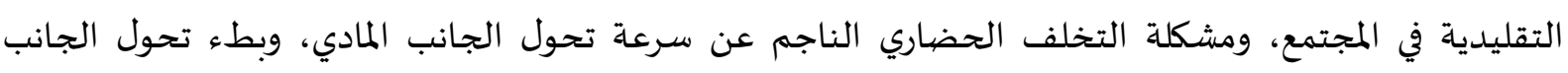
الحضاري القيمي في المجتمع.

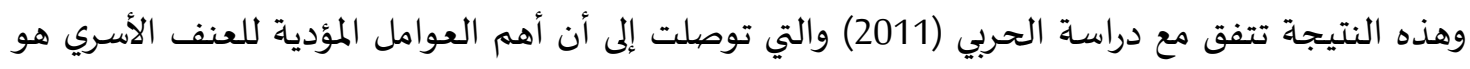

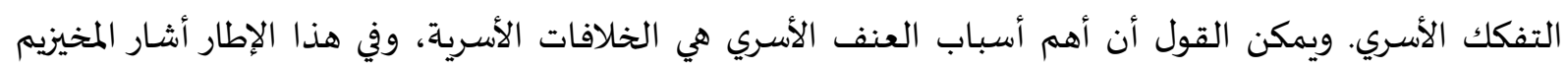

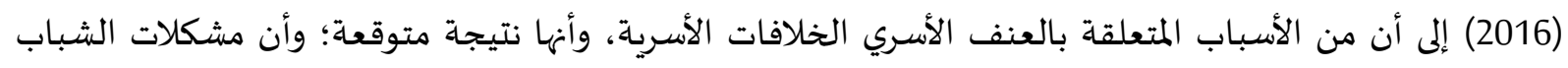

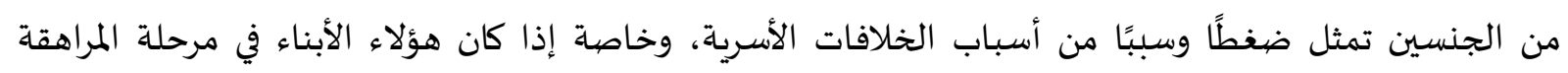
ويقابل هذا حرص الوالدين على مستقبل الأبناء وسلوكههم.

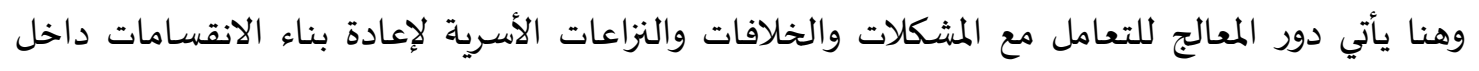

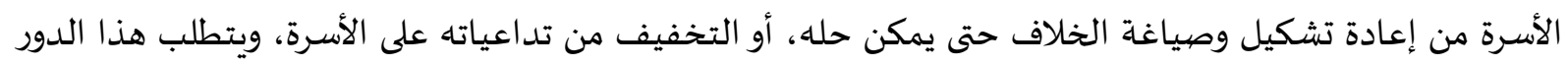

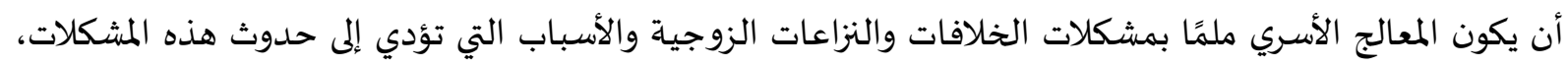

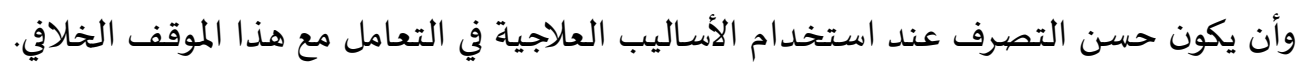

4- المعوقات التي تواجه تطبيق نظام الحماية من الإيذاء:

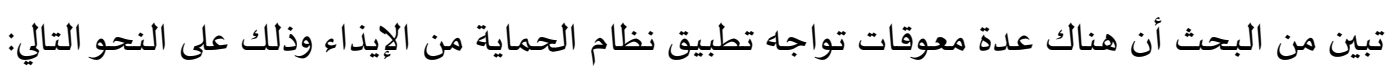

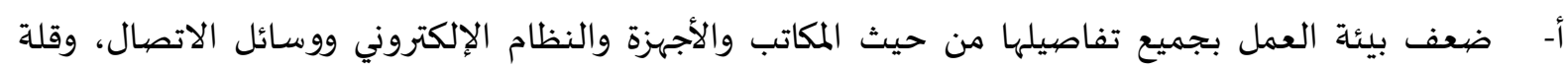

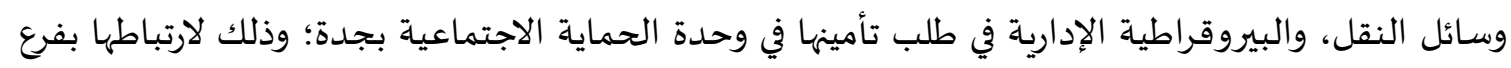

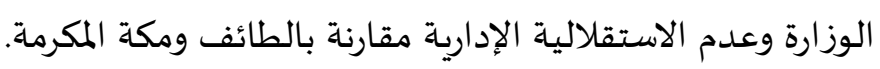

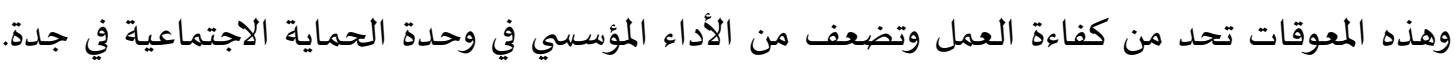

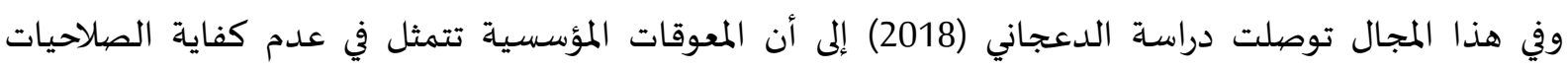
المخصصة للمؤسسة، مما يتسبب في ضعف القدرة على مواجهة مشكلة العنف الأسري، وتليها قلة الموارد والإمكانات المخصصة لمواجهة مشكلة العنف الأسري من خلال لجان الحماية من العنف والإيذاء.

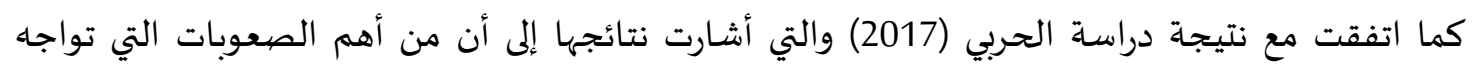

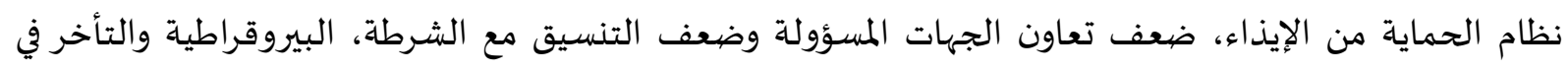

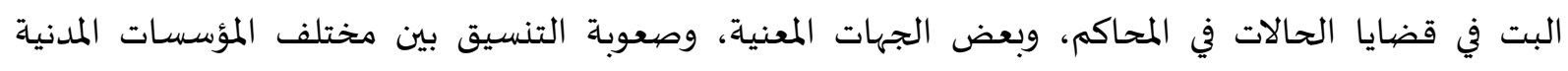
والجهات الأمنية.

ب- عدم وجود دار إيواء في مكة المكرمة واحتياج كثير من الحالات الدخول إلى الدار وصعوبة قبول الحالات في المناطق الأخرى. 
ج- قلة الكادر من الأخصائيين الاجتماعيين والأخصائيين النفسيين والإداريين.

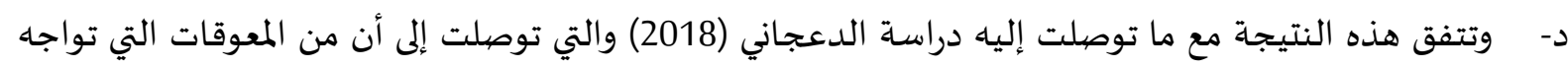

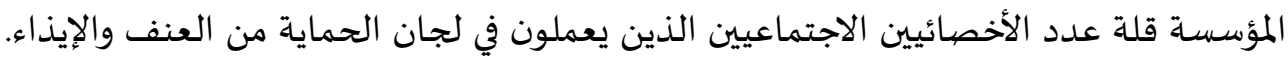

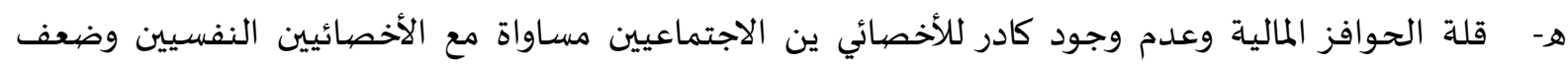

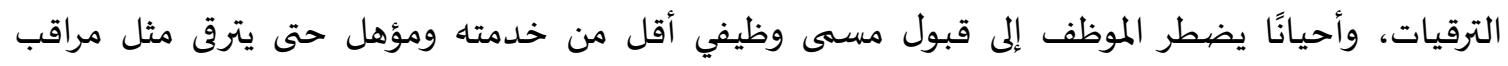

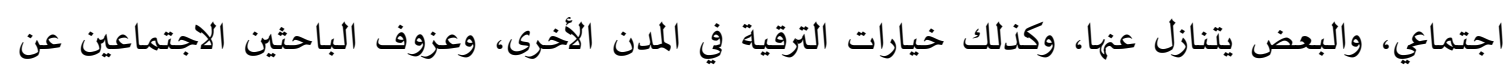
العمل في الحماية الاجتماعية. و- ضعف معرفة بعض الموظفين بدور الحماية الاجتماعية، وعدم وجود دليل مهام للعمل للموظفين، وقلة

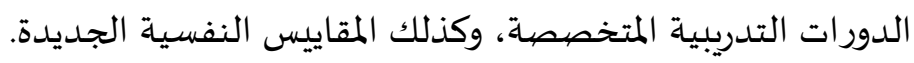

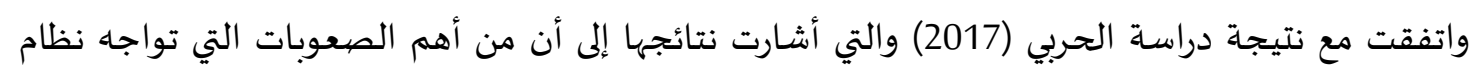

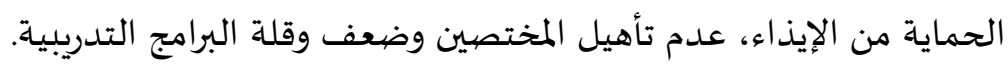

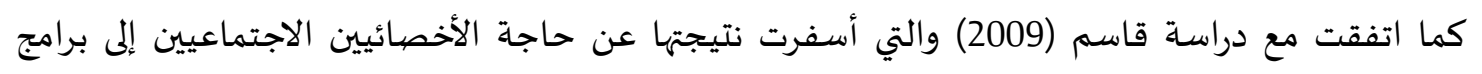

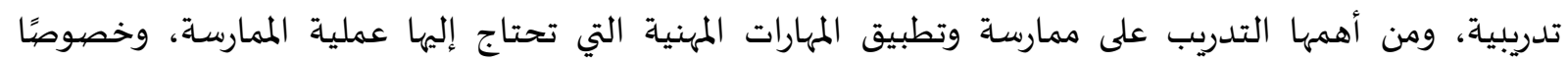
الاتجاهات الحديثة. ز- الموظفات المكلفات بدور المراقبات داخل الدار غير مؤهلات للتعامل مع حالات الحماية والعمل الاجتماعي،

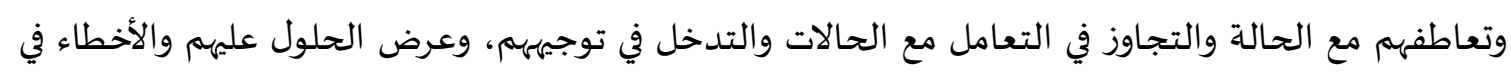
نقل الملاحظات. واتفقت مع نتيجة دراسة الحربي (2017) والتي أشـارت نتائجها إلى أن من أهم الصعوبات التي تواجه نظام

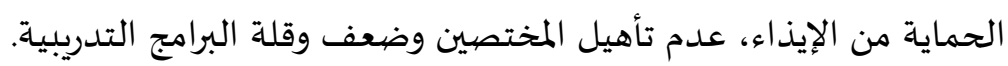

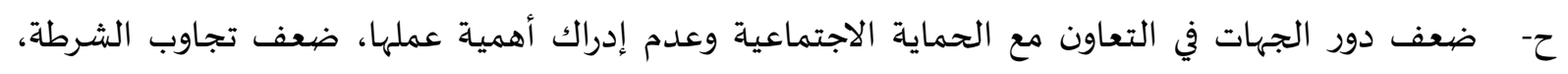

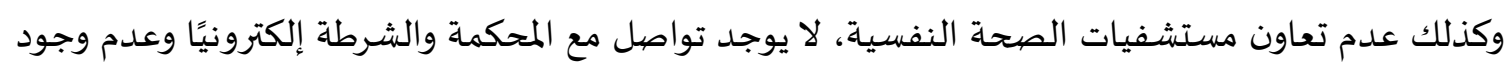

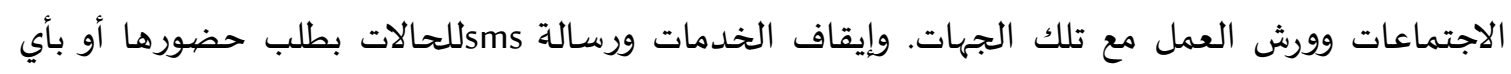
إجراء يستوجب، وعدم تسجيل المكالمات من خلال النظام.

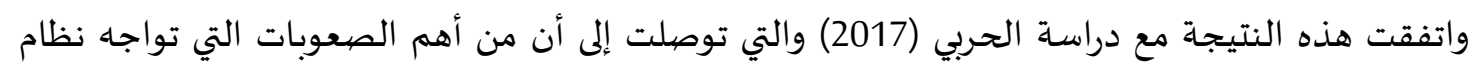

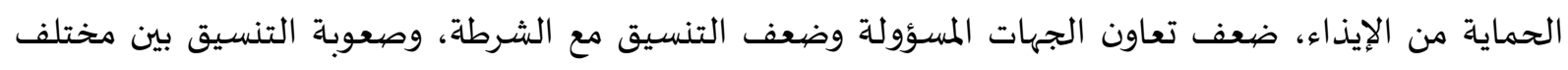
المؤسسات المدنية والجهات الأمنية. ط- مركز البلاغات لا يقيم البلاغات ولا يصنفها، وعدم وضوح البلاغ أحيانًا، نقص المعلومات، عدم وجود أرقام اتصال. ي- ازدواجية في الإجراءات بين الحماية والجهات الأخرى من حيث تقديم بلاغات مماثلة في الجهات الأخرى حتى

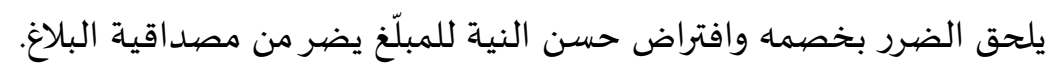

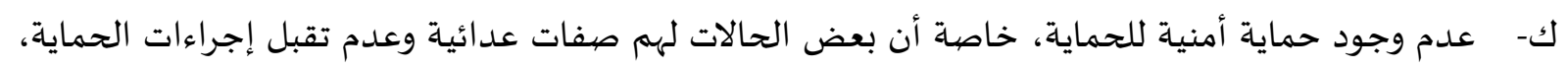

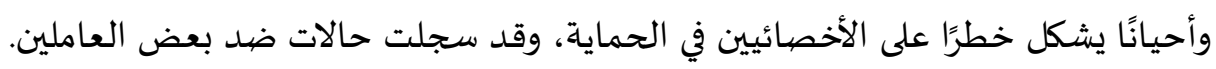

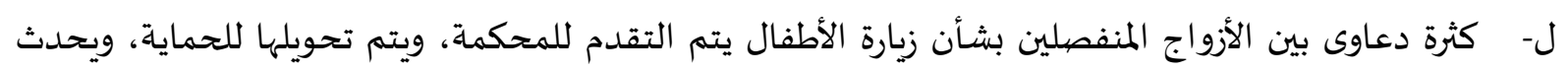
هناك ازدواجية بين المحكمة والحماية. 
م- ضعف الإدارة المرجعية المختصة في التعاطي مع الإثارة الإعلامية لبعض الحالات والشكاوى ينعكس سلبًا على

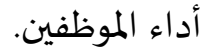

ن- قيام بعض المحاميين بتوجيه أطراف النزاع بالتقدم للحماية الاجتماعية ومحاولة إثبات الادعاء بالعنف

للاستفادة منها في التقاضي أمام المحكمة.

س- عدم وجود شركات مجتمعية وشركات داعمة للحماية الاجتماعية.

توصيات البحث:

1- - العمل على استقلال الحماية الاجتماعية كهيئة مختصية بالأسرة وفصلها عن وزارة العمل حتى يتم الحدد من

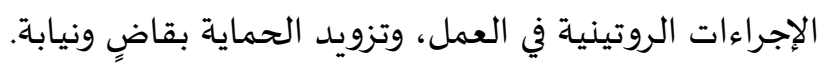

2- إنشاء مبانٍ خاصـة بالحماية تضم بيئة العمل للموظفين والدور الإيوائية للكبار والأطفال، وتوفير جميع الإمكانات

والتجهيزات اللازمة في هذه المباني. وإيجاد حراسات أمنية للحماية الاجتماعية.

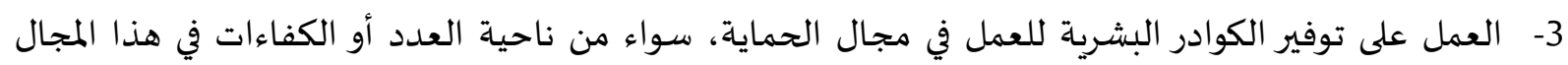

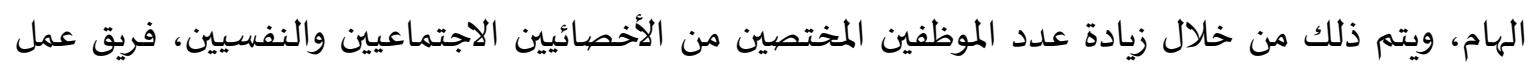

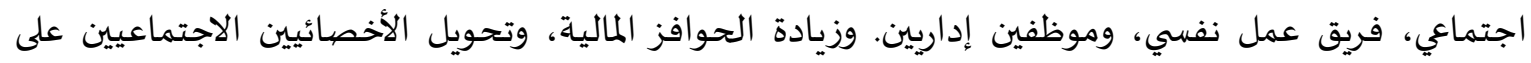

الكادر الوظيفي الصجي أسوةً بالأخصائيين النفسيين.

4- تطوير وتدريب الكادر على مباشرة الحالات، ودمج فريق العمل من الجنسين في مقابلات الحالة وجميع أطراف

البالاغ.

5- إعداد نماذج للعمل، خاصة دراسة الحالة، وتشمل البيانات الأولية، والتكوين الأسري، والعلاقات الأسرية،

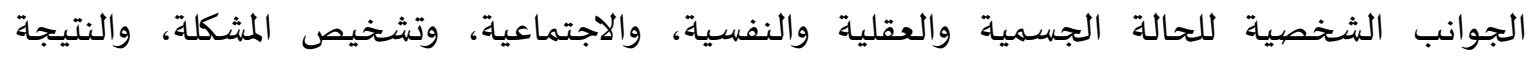

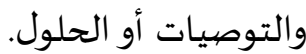

6- تطوير مركز البلاغات وإيجاد الموظفين المختصين بالعمل الاجتماعي من تخصص علم الاجتماع والخدمة

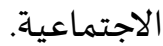

7- رصد الملاحظات وإعداد الدراسات والتعاون مع الجامعات في هذا الجانب، والعمل على التطوير المستمر،

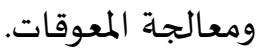

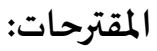

لاحظ الباحث ندرة في الدراسات الميدانية حول نظام الحماية من الإيذاء، لذا يوصي الباحث بإجراء المزيد

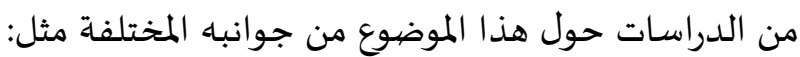

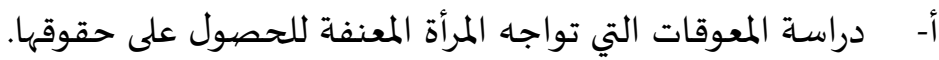

ب- المشكلات التي تواجه العاملين في مجال الحماية الاجتماعية في علاقاتهم بالجهات ذاتهات المات الاختصهاص.

قائمة المراجع.

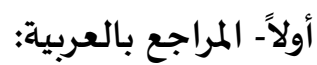

- الحربي، عبير سعد (2011)، تصور مقترح لتفعيل دور الخدمة الاجتماعية في التخفيف من المشكلات الاجتماعية

الناتجة عن العنف الأسري. 
- الحربي، مرام موسى (2017) دور نظام الحماية من الإيذاء في تحقيق الوقاية من العنف الأسري، جامعة نايف للعلوم الأمنية، رسالة دكتور اه.

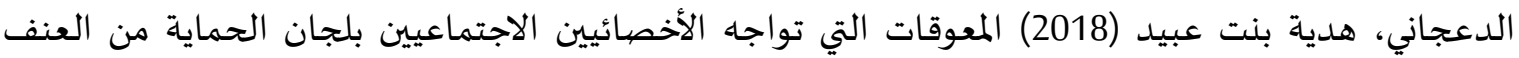
والإيذاء في المستشفيات الحكومية: دراسة ميدانية، رسالة ماجستير، جامعة الملك سعود، كلية الآداب.

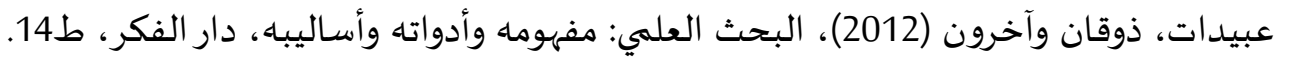

قاسم، أماني محمد رفعت (2009) نحو برنامج مقترح لتنمية المهارات المهنية للأخصائي ين الاجتماعيين في العمل دواتل

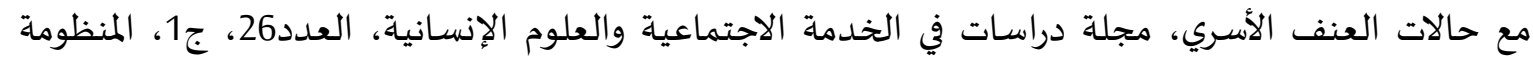
العربية. كرادشة، منير (2009) العنف الأسري، عالم الكتاب الحديث، الأردن، الطبعة الأولى.

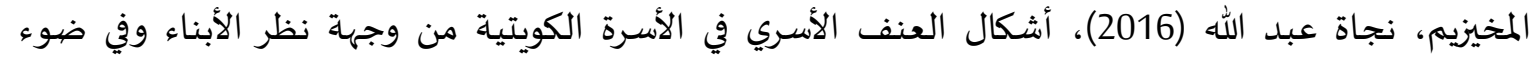

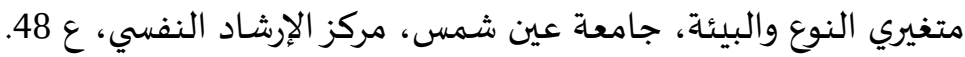
المعايطة، رائد عبد اللطيف (2014) دور إدارة حماية الأسرة في الحد من العنف الموجهاه ضد المرأة في محافظة الكرك، رسالة ماجستير، جامعة مؤته، الأردن. - النهاري، عبد العزيز، والسريحي، حسن (2002) مقدمة في مناهج البحث العلبي، دار خلود للنشروالتوزيع، جدة. ثانيًا- المراجع بالإنجليزية:

- Belshaku, S. (2016). Role of social worker in national center for victims of domestic violence. $\begin{array}{llllll}\text { European Scientific Journal, } 12 & \text { (23) Retrieved from }\end{array}$ http://search.proquest.com/docview/186?accountid=1.

- Payne,Tamika. (2017). Domestic Violence Recidivism: Restorative Justice Intervention Programs for First-Time, Domestic Violence Offenders. Dissertation Submitted in Partial Fulfillment of the Requirements for the Degree of Doctor of Philosophy, Walden University: Human Services Faculty. 